Ю. О. Ковтунов ${ }^{1}$, О. А. Макогон ${ }^{1}$, О. В. Ісаков ${ }^{1}$, Ю. В. Бабкін ${ }^{1}$, І. В. Калінін ${ }^{1}$, Р. Р. Лазута ${ }^{2}$

${ }^{1}$ Військовий інститут танкових військ НТУ “ХПІ”, Харків, Україна

${ }^{2}$ Військовий інститут телекомунікацій та інформатизації імені Героїв Крут, Київ, Україна

\title{
ВИКОРИСТАННЯ МАТЕМАТИЧНОГО АПАРАТУ НЕЧІТКОЇ ЛОГІКИ ДЛЯ ФАЗЗІФІКАЦЇ̈ ТА АЛГОРИТМІЗАЦІЇ РОБОТИ СИСТЕМИ ІНТЕРАКТИВНОГО МОНІТОРИНГУ ТРАНСПОРТНИХ КОМУНІКАЦЙ
}

\begin{abstract}
Анотація. Предметом вивчення в статті є моніторинг транспортних комунікацій при застосуванні сучасних технологій інтелектуалізації транспортних засобів. Метою статті $\epsilon$ розроблення математичного апарату для створення інтелектуального програмного забезпечення мобільного інтерактивного моніторингу транспортних комунікацій. Завдання дослідження: приведення опису системи інтерактивного моніторингу транспортних комунікацій до нечіткого виду шляхом визначення лінгвістичних змінних; проведення аналогії між кількісними оцінками підсистем і ланок системи і їх нечітким описом; на основі фаззіфікації проведення алгоритмізації задач моніторингу транспортних комунікацій; проведення динамічного аналізу процесу моніторингу транспортним засобом, обладнаним інформаційно-обчислювальним комплексом. Методологічною основою дослідження стали загальнонаукові та спеціальні методи наукового пізнання: теорія систем, нечітких множин, основні положення інформаційної теорії керування та розрізнення. Отримані такі результати: процес моніторингу транспортних комунікацій поданий як результат нормалізації даних, їх структурної й прагматичної обробки; визначений оператор фаззіфікації спостережуваного динамічного процесу моніторингу транспортних комунікацій; надане математичне підгрунтя алгоритмізації процедури керування процесом моніторингу; проведений динамічний аналіз процесу моніторингу транспортним засобом, обладнаним інформаційно-обчислювальним комплексом. Висновки. Системи інтерактивного моніторингу транспортних комунікацій нечіткого виду може бути формально описана шляхом визначення лінгвістичних змінних та їх значень - термів. Фаззіфікація спостережуваного динамічного процесу моніторингу транспортних комунікацій може бути подана у вигляді подвійного перетворення динамічної функції. Алгоритмізації цієї процедури можлива шляхом визначення відповідності характеристик спостережуваних динамічних процесів процедурам оцінки термів за допомогою функції приналежності лінгвістичної змінної, що характеризує цей процес.
\end{abstract}

Ключов і слов а: нечітка логіка, фаззіфікація, моніторинг транспортних комунікацій, інформаційно-обчислювальний комплекс.

\section{Постановка проблеми та завдання дослідження}

Впровадження новітніх інформаційних технологій дозволяє автоматизувати процеси, які раніше виконувалися безпосередньо за участю людини. На формальному рівні оцінка стану такої складної системи як транспортні комунікації пов'язана 3 нормуванням участі у ньому процесі людини. Створення мобільних інформаційно-обчислювальних комплексів (IOK) як основного інструменту інтерактивного моніторингу транспортних комунікацій пов'язано із розширенням списку контролюємих параметрів при одночасному зменшенні участі людини як джерела суб'єктивних оцінок. Зазвичай, водій-оператор, який знаходиться за кермом автомобіля, обладнаного IOК, суб'єктивно сприймає стан ділянки дороги, що аналізується. Однак, саме такий суб'єктивізм несе корисну інформацію, яка дозволяє вірно прийняти рішення щодо дійсного стану відповідної ділянки. Виходячи з цих обставин, авторами вважається актуальним дослідження методів поєднання суб'єктивізму оцінок стану ділянки дороги $з$ точним технічним розрахунком.

Аналіз останніх досліджень і публікацій стосовно зазначених вище питань засвідчує, що теоретичні засади створення програмного забезпечення мобільного та відповідний математичний апарат наведено у дослідженнях з моніторингу автомобільних доріг [1-4]. Це так званий нечіткий підхід або фаззіфікація. Першим кроком до використання нечіткого фаззі підходу до моделювання складних транспортних об'єктів і систем є завдання фаззіфікації формального опису їх спостережуваних динамічних процесів руху. Нечітка логіка $є$ областю не традиційної математики, що сьогодні широко представлена у фундаментальному й прикладному науковому виданнях. Існуючі підходи до рішення завдання фаззіфікації в транспортних додатках відрізняються певним суб'єктивізмом. Якщо це й припустимо в організаційних системах, то в технічних і організаційно-технічних системах потрібні суворі кількісні оцінки, виключення суб'єктивної думки людини. Це, насамперед, можна віднести до нових транспортних додатків нечіткої логіки. Так, у завданнях моніторингу транспортних машин, систем і комунікацій, де раніше використалися експертні оцінки, близькі до використання апарата лінгвістичних змінних, $є$ протиріччя між можливостями кількісної обробки даних технічних параметрів і використанням “неточних" логічних виводів $[5,6]$.

Метою статті $\epsilon$ розроблення математичного апарату для створення інтелектуального програмного забезпечення мобільного інтерактивного моніторингу транспортних комунікацій. Для досягнення мети визначені завдання дослідження: приведення опису системи інтерактивного моніторингу транспортних комунікацій до нечіткого виду; проведення аналогії між кількісними оцінками під- 
систем і ланок системи і їх нечітким описом; на основі фаззіфікації проведення алгоритмізації задач моніторингу транспортних комунікацій; проведення динамічного аналізу процесу моніторингу транспортним засобом, обладнаним інформаційнообчислювальним комплексом.

\section{Виклад основного матеріалу}

1. Основні поняття у моніторингу транспортних комунікацій. Представимо процес моніторингу транспортних комунікацій як результат нормалізації даних, їх структурної й прагматичної обробки. Транспортні комунікації являють собою складну організаційно-технічну систему. Таке представлення основане на те, що в їх склад входять як технічні, так і організаційні об'єкти.

Під моніторингом транспортних комунікацій слід розуміти безперервні просторово-часові спостереження протяжного об'єкту 3 метою визначення його експлуатаційних параметрів.

Основними поняттями у моніторингу транспортних комунікацій будемо вважати такі як протяжний об'єкт, стан протяжного об'єкту, параметри протяжного об'єкту, база даних про стан протяжного об'єкту, інформаційно-обчислювальний комплекс.

Під протяжним об'єктом будемо розуміти споруду великої довжини, на котру націлені любі дії (експлуатація цієї споруди, спостереження, контроль, тощо). Математично цей об'єкт, у котрому один з геометричних параметрів значно перевищує інші, точніше можна сказати, що протяжні об'єкти це такі об'єкти, основною характеристикою котрих являється значне перевищення однієї з характеристик 3 набору параметрів, визначаючих властивості об'єкту дослідження. Протяжний об'єкт - це об'єкт, що має велику площину, тобто простирається у декількох напрямках. Це може бути як сейсмічно небезпечна ділянка землі, так і будь яке вертикальна об'ємна споруда. Стан протяжного об'єкту - це точно визначена умова чи властивість, яка може бути впізнаною при повторному появленні (як і в випадку любої складної системи).

Параметрами протяжного об’єкту можна назвати комплекс показників, котрі характеризують стан об'єкту дослідження. Окремим випадком протяжного об'єкту є лінійний об'єкт. Але у відмінності від протяжного, для лінійного об'єкту має значення тільки одна характеристика, тоді як для протяжного необхідно аналізувати значення всього набору характеристик як в “подовжньому”, так і у “поперечному” напрямках. Під базою даних про стані протяжного об'єкту розуміється сукупність даних, в котрих міститься відомості о значеннях параметрів протяжного об'єкту.

Слід підкреслити, що дані про стан протяжного об'єкту мають різновид ний характер. Це не тільки дані однієї природи, а множина техніко-економічних характеристик, котрі дають найбільш повну уяву про об'єкт, його ролі та стану. Особо виділяються ергономічні показники, так як досліджуваний об'єкт має яскраво виражений людино-машинний характер [7-9].
2. Приведення точних характеристик транспортної технічної системи моніторингу до “нечіткого" виду. Нехай технічний об'єкт або система формально описується оператором Y, що перетворить спостережувану динамічну змінну $\mathrm{x}(\mathrm{t})$ - прообраз оператора Y, що однозначно визначає відповідний спостережуваний динамічний процес. Для транспортної системи такий динамічний процес - це процес руху транспортного засобу. У найпростішому випадку результатом перетворення $\epsilon$ образ оператора $y(t)$. Логічно вважати процес спостереження такої системи динамічним моніторингом. Для переходу від суб'єктивних оцінок спостережуваного об'єкта або системи покладемо, що $y(t)$ однозначно відповідає лінгвістичної змінної в області визначення нечіткої моделі спостережуваного динамічного процесу.

Тоді обмежена множина термів такий лінгвістичної змінної визначається специфікою спостережуваного динамічного процесу. Формально:

$$
y(t)=Y[x(t), t]
$$

де $y(t)$ - образ оператора $Y ; x(t)$ - прообраз оператора $Y ; t-$ поточний час.

Якщо $x(t)$ відповідає певна точка $x_{n} 3$ множини $X$, то в пропонованій постановці конкретне значення образа оператора $y(t)$ відповідає одному з термінів. До цього терміна ставитися не єдине значення $y_{m}=Y$, а кілька суміжних значень.

Якщо процес спостереження $x(t)$ є моніторингом, то послідовності $2 k+1$ відсіків $y(t)$ у діапазоні

$$
\left\{y_{m-c}, y_{m-c-1}, \ldots, y_{m}, \ldots, y_{m+c-1}, y_{m+c}\right\} \in y(t)
$$

є кількісна оцінка одного з термів відповідної лінгвістичної змінної.

Таким чином, розглядаючи операторне перетворення (1), треба поряд з кількісною відповідністю $X \rightarrow Y$ також аналізувати відповідність $Y \rightarrow L$, де $L-$ множина термів лінгвістичної змінної, аналогом якої є $y(t)$. Назвемо $P$ оператором фаззіфікації спостережуваного динамічного процесу, аналогом якого є значення образа $y(t)$ значень функції $x(t)$, що реєструються:

$$
e(S)=P[y(t), S],
$$

де $S$ - аргумент, що характеризує відповідність $2 k+1$ значення $y_{m}$ в діапазоні від $y_{m-c}$ до $y_{m+c}$ терму $L(S)$ поточному значенню часу $t$ у момент реєстрації.

Порівняно проста система операторних співвідношень (3) може бути просто реалізована, якщо вона формалізуємо й кількісно оцінювана як ступінь приналежності значень $x(t)$,що реєструються, відповідний терму $l(s)$, а час поточний $\mathrm{t}$ відповідає $\mathrm{s}$.

Припустимо, що фаззіфікація спостережуваного динамічного процесу є таке подвійне перетворення динамічної функції $x(t)$, що реєструється:

$$
\begin{aligned}
& y(t)=Y[x(t), t] ; \\
& l(s)=L[y(t), s] ;
\end{aligned}
$$




$$
S \in S \rightarrow T, t_{p} \in T
$$

Таким чином, алгоритмізація цієї процедури можлива шляхом визначення відповідності характеристик спостережуваних динамічних процесів процедурам оцінки термів за допомогою функції приналежності лінгвістичної змінної, що характеризує цей процес.

Така процедура полягає в знаходженні механізму розрахунку кількості термів, точності реєстрації $x(t)$ і розрізнення результатів оцінки $y(t)$ необхідного динамічного процесу.

Розглянемо проблему загального завдання фаззіфікації в прикладній постановці, що відповідає транспортним додаткам (завдання моніторингу дорожнього середовища).

3. Фаззіфікація системи моніторингу транспортних комунікацій. Така система являє собою спостерігача, що рухається, безпосередньо виконуючий вимір й оцінку стану об'єктів, що рухаються, і дороги. Формально образ відповідного оператора цієї системи й лінгвістична змінна є результатом подвійного перетворення значень спостережуваної змінної $x(t)$ в одномірному випадку. Наприклад, у русі базового транспортного засобу безупинно оцінюється або його швидкість у транспортному потоці $\mathrm{v}(\mathrm{t})$ або рівність, коефіцієнт зчеплення коліс транспортного засобу з поверхнею дороги $\mathrm{r}(\mathrm{t})$. Таким чином, $x(t)$ - деяка узагальнена оцінка як транспортної машини, так і дороги, якщо вважати, що транспортна система є об'єднанням множини машин М и дороги А, по якій ці машини рухаються.

Оператор фаззіфікації є перетворення значень спостережуваних динамічних змінних $x(t)$ з області множини х в одну із крапок нечіткої множини $S$. Реальний прототип множини $S$ - послідовність деяких фіксованих крапок відповідної транспортної комунікації (автомобільної дороги).

Фізично цим процесам відповідає реєстрація значень спостережуваної динамічної змінної $x(t)$, їхня інформація, приведення до заздалегідь певної системи відліків $y(t)$ і прагматична обробка значень лінгвістичної змінної $l(s)$. При цьому, в результаті процесу фаззіфікації оцінка $l(s)$ виконується щодо не часу $t$, а у відповідності властивостей досліджуваного об'єкта в порівнянні з іншими аналогічними об'єктами.

Введемо припущення, що моніторинг грунтується на методі аналогій. Таким чином, бальні оцінки є прототипом лінгвістичних змінних. Тоді в тих системах, де такі оцінки використаються, можна перейти від певного суб'єктивізму експерта до точного кількісного аналізу результатів спостережень на основі лінгвістичних змінних.

Наслідком є рішення задачі визначення фізичного розрізнення спостережуваного динамічного процесу по споживчому розрізненню, що задається бальною оцінкою.

Відповідно до інформаційної теорії керування розрізняють фізичний i споживчий поріг розрізнення спостережуваного динамічного процесу.
Якщо це оператор $Y$ перетворення прообразу $x(t)$ у значення образа $y(t)$, то поріг розрізнення $E_{x}$ рівний найменшої різниці суміжних значень

$$
x(t): \Delta_{x}=\min \left(x_{n}-x_{n+1}\right),
$$

$€$ фізичним порогом розрізнення спостережуваного динамічного процесу.

Відповідно

$$
E_{y}=\min \left(y_{m}-y_{m+1}\right)-
$$

споживчий поріг розрізнення спостережуваного динамічного процесу.

Варто помітити, що для ясності викладу під спостережуваним динамічним процесом автор розуміє одномірний випадок зміни величини $x(t)$, а спостереження - реєстрація значень $x_{n} \in x(t)$.

Кількість $d_{x}$ різних значень $x(t)$ або дискретних відліків визначається порогом розрізнення $E_{x}$ так, що $n=1,2, \ldots, d_{x}-1, d_{x}$. За аналогією кількість $d_{y}$ різних значень $y(t)$ визначається в такий же спосіб. Тому

$$
\begin{aligned}
d_{x}= & \frac{\max _{n} X_{n}-\min _{n} X_{n}}{E_{x}} ; \\
d_{y}= & \frac{\max _{m} Y_{m}-\min _{m} Y_{m}}{E_{y}} .
\end{aligned}
$$

У технічних системах $E_{x}$ визначається фізичними властивостями спостережуваного процесу, а $E_{y}$ - потребами користувача. Стосовно лінгвістичної змінної $l(s)$ спостережуваного процесу не можна говорити про відповідний поріг розрізнення тому що для неї справедливі не кількісні, а логічні оцінки. Однак можна затверджувати, що кількість iii термів дорівнює $d_{x}$, а значення $y_{n} \in y(t), \epsilon$ кількісною оцінкою відповідною оцінкою відповідає лінгвістичної змінної $l(s)$.

Таким чином, отримані співвідношення (1) (4) дозволяють порівняно просто вирішувати завдання як саме фаззіфікації, так і визначення відповідних характеристик цього процесу: порогів розрізнення, значень діапазонів зміни термів та відповідно точності реєстрації даних.

4. Алгоритмізація задач моніторингу транспортних комунікацій. Згідно з твердженням, що основною характеристикою процесу моніторингу $є$ відстань від умовного початку траси $l$, що належить метричному простору $L$, можна визначити оператор перетворення $Q$ результатів виміру $y(t)$ за результатами вимірів параметрів $x(t)$. Це перетворення виконується у часовому просторі $T, L_{Q} \subset L$ та $L_{X} \subset L$.

Однак, $L_{Q}$ та $L_{X}$ незважаючи на те, що вони належать одному метричному простору $L, \epsilon$ множинами

$$
L_{Q} \cap L_{X}=0,
$$


що не перехрещуються. Це пояснюється різною фізичною природою множини функцій $x(l)$ та множини функцій $Q(l)$.

Для дослідження цих перетворень найбільш ефективним $\epsilon$ використання математичного апарата функціональних похідних.

Вони вираховуються за подвійною границею такого вигляду для оператора

$$
\begin{gathered}
y(t)=Y[x(t), t]: \\
\frac{\partial y}{S_{x}}=\frac{\Delta y}{\Delta x \cdot \Delta t}, \\
\Delta x \rightarrow 0, \\
\Delta t \rightarrow 0,
\end{gathered}
$$

де $\frac{\partial y}{S_{x}}-$ функціональна похідна образу оператора $y(t)$ з прообразу $x(l) ; \Delta x$ - приріст прообразу оператора $y ; \Delta y$ - приріст образу оператора $y$.

У результаті розрахунку (5) визначається зміна образу оператора не тільки залежно від зміни аргументу $t$, але і прообразу х(1).

Тому можна виконати для реального прикладу руху транспортного засобу, обладнаного IOK, розрахунок подвійної межі $\frac{\partial l}{\partial S}$, вираховуючи значення $\frac{\Delta l}{\Delta \alpha \cdot \Delta t}$ для оператора перетворення напрямку руху (кут $\alpha$ ) та часу $t$ у відстань $l$.

У такому випадку образ оператора - довжина $l$ ділянки транспортної комунікації. Прообраз і образ оператора визначені на одному метричному просторі: часової вісі множини вимірів $\left\{t_{i}\right\} \in T$. Це дасть можливість представити функцію $l(t)$ на інтервалі $\left[t_{0}, t_{n}\right]$ як систему співвідношень, що мають такий вигляд:

$$
\Delta l_{n}=\left.\frac{\partial l}{\partial S_{t}}\right|_{t=t_{n}} \cdot \Delta t+\left.\frac{\partial l}{\partial S_{\alpha}}\right|_{\alpha=\alpha_{n}} \cdot \Delta \alpha
$$

Представимо $\Delta l_{i}$ як аналітичну залежність, що отримана в результаті практичних вимірів відстані $\Delta l=\Delta l_{i+1}-l_{i}$ проміжок часу $\Delta t$ при зміні азимуту $\Delta \alpha$.

Для цього визначимо пороги розрізненості довжини, часу та кута $\xi_{l}, \xi_{t}, \xi_{\alpha}$. Тоді можна стверджувати, що:

$$
\xi_{l}=\left.K_{t} \frac{\partial l}{\partial S_{t}}\right|_{t=t_{i}} \cdot \Delta \xi_{t}+\left.K_{\alpha} \frac{\partial l}{\partial S_{\alpha}}\right|_{\alpha=\alpha_{i}} \cdot \Delta \xi_{\alpha},
$$

де $K_{t}$ та $K_{\alpha}-$ коефіцієнти, що враховують різні розмірності $t$ i $\alpha$.

Можна також розрахувати реальне значення $l_{i}^{u}$ довжини в точці $t=t_{i}$ при виконанні вимірів 3 кроком, що визначаються $\xi_{t}$ i $\xi_{\alpha}[10]$ :

$$
\begin{gathered}
l_{i}^{u}=l_{i}- \\
-\left[\left.K_{t} \frac{\partial l}{\partial S_{t}}\right|_{t=t_{i}} \cdot \Delta \xi_{t}+\left.K_{\alpha} \frac{\partial l}{\partial S_{\alpha}}\right|_{\alpha=\alpha_{i}} \cdot \Delta \xi_{\alpha}\right] .
\end{gathered}
$$

5. Динамічний аналіз процесу моніторингу транспортним засобом, обладнаним ІОК. Будемо вважати, що вхід системи - обертання коліс автомобіля. Розглянемо випадок, що відповідає ситуації, при якій за одне обертання колеса система отримає один імпульс керування. Тоді маємо чотири джерела імпульсів з інтервалами між суміжними імпульсами циклу $t_{1 ц}, t_{2 ц}, t_{3 ц}, t_{4 ц}$, що відповідно визначаються часом оберту колеса.

Таким чином,

$$
\begin{aligned}
& t_{1 u}=\frac{c_{1}}{v_{1}}, \\
& t_{2 u}=\frac{c_{2}}{v_{2}}, \\
& t_{3 u}=\frac{c_{3}}{v_{3}}, \\
& t_{3 u}=\frac{c_{3}}{v_{3}}
\end{aligned}
$$

де $c_{1}, c_{2}, c_{3}, c_{4}$ - довжини кіл коліс; $v_{1}, v_{2}, v_{3}, v_{4}-$ швидкості обертання коліс, тоді як для першого колеса;

$$
v_{1}=\frac{c_{1} \cdot f}{N_{1}},
$$

де $f$ - частота заповнення часового інтервалу, що визначається обертанням колеса; $N_{1}$ - кількість імпульсів заповнення.

У цьому випадку процес моніторингу складається з послідовності циклів $T_{u}$, що повторюються. Тоді можна визначити умову вимірювання $v_{1}, v_{2}, v_{3}$, $\mathrm{v}_{4}$ таким чином:

$$
T_{u}>\max \left(t_{1 u}, t_{2 u}, t_{3 u}, t_{4 u}\right) .
$$

Реєстрація даних здійснюється за сигналами переривання процесора вимірювальним приладом обертання розподільчого вала. Реєструються послідовності імпульсів, що є результатом роботи цифрових приладів та аналогові сигнали, що є результатом роботи системи навігації.

Загальний час реєстрації $\mathrm{T}_{\mathrm{R}}$ визначається таким чином:

$$
T_{R}=t_{H}+t_{1 n}+t_{2 n}+t_{3 n}+t_{4 n}
$$

де $t_{t}$ - час сигналів вимірювальних приладів руху; $t_{1 n}, t_{2 n}, t_{3 n}, t_{4 n}$, - час реєстрації сигналів прискорення коливань кузова транспортного засобу.

Керування процесом моніторингу можливо здійснювати за допомогою спеціальної програми. Крім цього здійснюється вивід даних на монітор та формування бази даних. 
Ці процедури та необхідна обробка подій комунікаційних портів виконується програмою, яку визначимо комунікаційною.

Результат роботи комунікаційної програми заповнення буфера даних і видача повідомлення головній програмі керування про необхідність записати отримані дані на жорсткий диск. Година роботи комунікаційної підпрограми - $\mathrm{T}_{\text {ком. }}$

Тоді

$$
T_{u}>\max \left(T_{\text {ком }}, T_{R}\right) .
$$

Очевидно, що нерівність (13) $є$ основною умовою нормальної роботи обчислювального комплексу. Співвідношення (11), (13) - це обмеження, що необхідні для організації роботи програмного забезпечення IOK [11].

\section{Висновки}

1. Системи інтерактивного моніторингу транспортних комунікацій нечіткого виду може бути формально описана шляхом визначення лінгвістичних змінних та їх значень - термів.

2. Фаззіфікація спостережуваного динамічного процесу моніторингу транспортних комунікацій може бути подана у вигляді подвійного перетворення динамічної функції.

3. Алгоритмізації цієї процедури можлива шляхом визначення відповідності характеристик спостережуваних динамічних процесів процедурам оцінки термів за допомогою функції приналежності лінгвістичної змінної, що характеризує цей процес.

\section{СПИСОК ЛІТЕРАТУРИ}

1. Алексієв В.О. Інтерактивний моніторинг автомобільних доріг: монографія / О.П. Алексієв, А.А. Видмиш, В.О. Хабаров.: - Винниця : ВНТУ, 2012. -144 с.

2. Хабаров В.О. Дорожники недополучают - государство теряет / В.О. Хабаров // Науковий вісник будівництва. - Х. : ХДТУБА. - 2002. - № 19. - С. $153-155$.

3. Перегон О.В. Моделювання руху транспортних машин у системі громадського пасажирського транспорту // Автомобильный транспорт. - Харьков: ХНАДУ, 2005. - Вып. 16. - С. 327-329.

4. Horowitz R. Automated Highway systems // Transportation systems IF AC Symposium, Chania, Greece, 1997. - pp. 452 463.

5. Малявин А.А. Разработка системы управления движением автомобиля с использованием нечеткой логики: дис. ... канд. техн. наук. 05.13.06. Москва. 2011. 180 с.

6. El Hajjaji A, Bentalba S. Fuzzy path tracking control for automatic steering of vehicles[J]. Robotics and Autonomous Systems, 2003, 43(4): 203-213.

7. Robert Fuller. Neural Fuzzy Systems. Abo Akademy University. Пер. с англ. С. В. Кряжевских, 1995.

8. Зиков I. С., Кучук Н. Г., Шматков С. І. Синтез архітектури комп'ютерної системи управління транзакціями е-learning. Сучасні інформаційні системи. 2018. Т. 2, № 3. C. 60-66. DOI: https://doi.org/10.20998/2522-9052.2018.3.10

9. Mozhaiev, M., Kuchuk, N. and Usatenko, M. (2019), "The method of jitter determining in the telecommunication network of a computer system on a special software platform", Innovative technologies and scientific solutions for industries, (4 (10), pp. 134-140. doi: $10.30837 / 2522-9818.2019 .10 .134$

10. Математические принципы нечеткой логики/ Новак В., Перфильева И., Мочкорж И. Пер с англ.; Под ред. Аверкина А.Н. - М.: Физматлит, 2006. - 352 с.

11. Мехатроніка транспортних засобів та систем. Алексієв О.П., Волков В.П., Калмиков В.І. Навчальний посібник. Харків: ХНАДУ. 2003. - 225 с.

Received (Надійшла) 24.05.2020

Accepted for publication (Прийнята до друку) 19.08.2020

\section{Using the mathematical apparatus of fuzzy logic for phasification and algorithmizations of the interactive monitoring system of transport communications}

Yu. Kovtunov, H. Makogon, O. Isakov, Yu. Babkin, I. Kalinin, R. Lazuta

Abstract. The subject matter of the article is the monitoring of transport communications using modern technologies of intellectualization of vehicles. The goal of the study is to develop a mathematical apparatus for creating intelligent software for mobile interactive monitoring of transport communications.. The tasks to be solved are: to reduce the description of the transport communications interactive monitoring system to a fuzzy form by defining linguistic variables; to draw an analogy between quantitative estimates of subsystems and links of a system and their fuzzy description; based on fuzzification, to carry out the algorithmization of monitoring tasks of transport communications; to conduct a dynamic analysis of the monitoring process with a vehicle equipped with an information and computer complex. General scientific and special methods of scientific knowledge are used. The following results were obtained: the process of monitoring transport communications is presented as a result of data normalization, their structural and pragmatic processing; the fassification operator of the observed dynamic process of transport communications monitoring is defined; provided mathematical basis for algorithmization of the monitoring process control procedure; a dynamic analysis of the monitoring process of a vehicle equipped with an information and computing system was conducted. Conclusions. Systems of interactive monitoring of fuzzy transport communications can be formally described by defining linguistic variables and their meanings - terms. Fuzzification of the observed monitoring transport dynamic process communications can be presented in the form of a dynamic function double transformation. Algorithmization of this procedure is possible by determining the compliance of the observed dynamic processes characteristics to the procedures for estimating terms using the membership function of the linguistic variable characterizes this process.

Keywords : fuzzy logic, fuzzification, monitoring of transport communications, information and computer complex. 